\title{
Coulisses
}

Revue de théâtre

8 | Eté 1993

Varia

\section{Théâtre Universitaire de Liège}

\section{(2) OpenEdition}

1 Journals

Édition électronique

URL : http://journals.openedition.org/coulisses/2581

DOI : $10.4000 /$ coulisses. 2581

ISSN : 2546-9460

Éditeur

Presses universitaires de Franche-Comté

Édition imprimée

Date de publication : 1 juillet 1993

Pagination : 30-31

ISSN : 1150-594X

\section{Référence électronique}

"Théâtre Universitaire de Liège », Coulisses [En ligne], 8 | Eté 1993, mis en ligne le 15 mars 2019, consulté le 23 octobre 2019. URL : http://journals.openedition.org/coulisses/2581 ; DOI : 10.4000/ coulisses. 2581

Ce document a été généré automatiquement le 23 octobre 2019.

Coulisses 


\section{Théâtre Universitaire de Liège}

\section{Le metteur en scène}

\section{Robert Germay}

9-12-40

1 Titulaire d'un doctorat en Philosophie et Lettres sur Bertold Brecht et ses suites dans le théâtre allemand des années 50, Robert Germay est Maître de Conférences à l'Université de Liège où il enseigne la théorie et la pratique du théâtre ainsi que la méthodologie des arts et les sciences de la communication. Il est directeur des Théâtres Universitaires de Liège et des Rencontres Internationales de Liège. En tant que spécialiste du théâtre allemand du domaine germanique, il participe à de nombreux festivals et colloques internationaux (Casablanca, Montréal, Budapest, Puebla, Glasgow, ...). Il a réalisé de nombreuses mises en scène amateurs et professionnelles à partir d'œuvres pour l'essentiel de langue allemande: G. Buchner, B. Brecht, M. Frisch, O. von Horvath, T Bernhard, R.W. Fassbinder, ... 


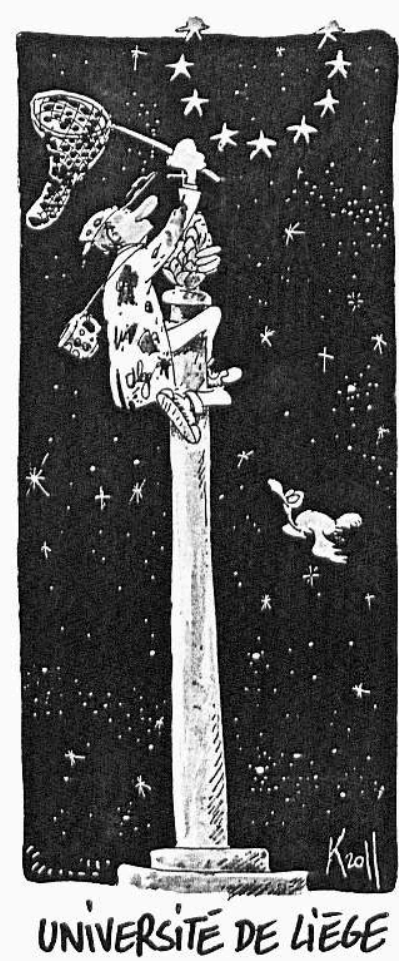

\section{Son point de vue}

Cymbeline ou une pièce de trois heures pour que tout se noue, s'entrenoue, se renoue et finalement se dénoue. Trois heures de spectacle, c'est long; trois heures vers la paix, à l'heure actuelle dans notre monde, c'est négligeable. Et pourtant, si comme pour Cymbeline, chacun consacrait trois heures pour aller au fond des choses et dépasser les simples apparences de lettres, d'anneaux, de robes, de costumes et de parures, ce serait aussi un grand pas pour notre humanité. Voici donc le message de cymbeline: les apparences sont trompeuses. Prenons-y garde! C'est le leitmotiv qui guidera notre travail. Nous avons choisi de travailler dans la langue de Shakespeare. Il s'est agi d'abord de chercher à réduire sensiblement la longueur de la pièce. Chaque acteur et participant a sélectionné 3 ou 4 monologues de Cymbeline, monologues - "envolée lyrique sur un thème shakespearien " - retenus par chacun pour les idées, les sentiments, actions... qui y sont développés, pour leurs apports à la mise en scène ou à l'anecdote. 34 extraits ont été retenus, d'où il ressort pour tous que cymbeline est beaucoup plus qu'une belle histoire d'amour et par sa multiplicité, nous offre un résumé de l'œuvre de Shakespeare. Tous ces monologues sont reliés au niveau de l'anecdote par la présence d'un narrateur qui pourrait être Imogène, Jupiter, Pisanio... ou tout autre personnage de la pièce, voire même extérieur à la pièce. Un travail en improvisations s'est fait en dégageant le point de vue particulier d'un des personnages de la pièce, par exemple Imogène, sur l'ensemble du spectacle. 


\section{Les étudiants sur scène}

Christophe DEBATICE

Françoise JAMART

Jean-Marc LELABOUREUR

Pascal RENARD

Théâtres Universitaires Liégeois

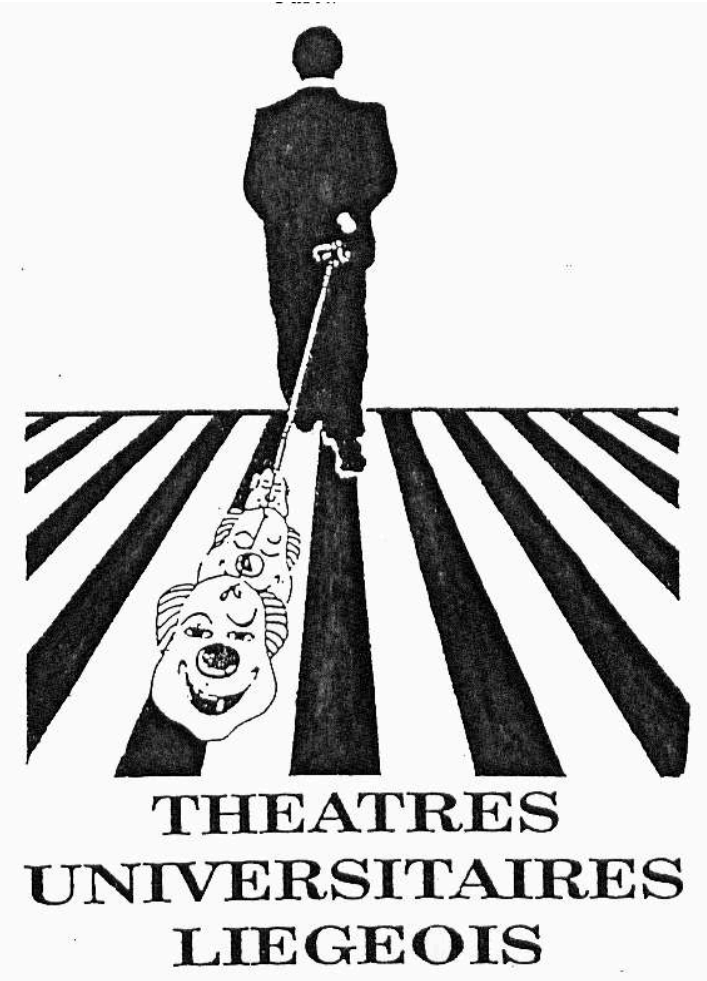

\section{Le T.U.}

Les Théâtres Universitaires Liégeois (T.U.L.) sont constitués de deux groupes distincts :

4 - le Théâtre Universitaire Liégeois (TULg) qui existe depuis 1941 et accueille tous les passionnés, universitaires ou non, des diverses techniques du spectacle. Il leur propose d'élaborer un spectacle qui sera monté en une saison puis partira en tournée la saison suivante en Belgique et à l'étranger.

5 - le Théâtre des Germanistes Liégeois (TLG), créé en 1964, joue un répertoire en langue allemande et anglaise, ce qui permet aux étudiants qui le composent de perfectionner leurs connaissances en langues, tout en participant à des activités théâtrales de haut niveau. Ces deux groupes qui ont fusionné il y a peu ont monté, souvent créé, d'innombrables spectacles : des classiques grecs ou français aux contemporains belges, allemands ou polonais, d'Aristophane à Fassbinder, d'Erasme à Tom Stoppard... Le T.U.L. a réalisé de nombreuses tournées en Belgique et à l'étranger: Vilnius, Paris, Casablanca, Zagreb, Montréal, ... 